\title{
Signalling Pathways and Gene Expression Profiles in Prostate Cancer
}

\author{
Sophia Marsella-Hatziieremia, Pamela McCall and Joanne Edwards \\ University of Glasgow \\ $U K$
}

\section{Introduction}

In general, cancer, encompassing prostate cancer (PCa), is a disease that utilises signalling pathways to progress through the uncontrolled proliferation of cancerous cells. Although the mechanisms of how the cells evade intrinsic or extrinsic signals of death and keep on dividing is not completely understood, there is a plethora of evidence that point to certain signalling molecules that are crucial conveyors of the fine tuning that slightly differs in cancer in comparison to control states. The present chapter provides a detailed description of the key regulators of PCa cell life and unveils their closely communicating proteins that aid in the fine tuning of the cancerous state.

\section{Androgen receptor (AR) signalling}

A major insight into the potential role of androgens in PCa came almost 70 years ago, from the observation that castration of patients with metastatic PCa resulted in a marked reduction in the levels of prostate specific antigen (PSA), a PCa serum acid phosphatase marker (Huggins and Hodges, 1941). In the same study, injection of androgens in some PCa patients resulted in significant increase of PSA. This clearly demonstrated the androgen dependency of PCa. The treatment of PCa has been based on inhibition of the synthesis or action of the ligand (testosterone and its active metabolite 5-diydrotestosterone (5-DHT)) on the androgen receptor (AR). In addition, there are numerous evidence that demonstrate the involvement of $\mathrm{AR}$ in $\mathrm{PCa}$ progression especially castration-recurrent $\mathrm{PCa}$, despite the absence of circulating testicular androgens.

As activation of the AR is associated with induction of proliferation and apoptosis in PCa cells, manipulation of androgen-AR relationship such as non steroidal AR antagonists such as bicalutamide and flutamide in conjunction with chemical or surgical castration is the main therapeutic option available to patients with locally advanced or metastatic cancer. However, the AR has been demonstrated to be activated even in castrate conditions, independent of testicular androgens. Mechanisms known to be involved with AR transactivation are: increased expression of receptor which allows its activation even in low levels of andrenal androgens, mutation of $A R$, non canonical variants of AR, modified expression or activity of AR coregulators and cross talk with other pathways regulating survival, cell death and proliferation of PCa cells. Usually a combination of these mechanisms occur simultaneously to provide PCa cells with an increase in the expression of genes that regulate proliferation and apoptosis. 
Numerous studies, initiated almost a decade ago, are dedicated in unravelling androgen regulated gene expression in both normal and tumorgenic prostate cells (please refer to review for complete references; Dehm and Tindall, 2006). The majority of large scale studies have been performed in LNCaP cells based on their AR-sensitive properties. The number of genes regulated by the function of androgens through the AR was recently estimated to be between 10,570 and 23,448 polyadenylated RNAs, however this number is set to grow if microRNAs are included (Dehm and Tindall, 2006). Furthermore, a recent study utilising a microarray analysis of androgen related genes in the cell line LNCaP has demonstrated that a large number of genes falling under the regulation of androgens are still of unknown function (Ngan et al., 2009). The genes regulated by AR regulate functions of the prostate cell related to cell proliferation, cell cycle, survival, death, lipid and steroid metabolism, protein products resulting from gene fusions and microRNAs.

AR signalling that regulates cell proliferation and apoptosis usually arises from cross-talk of the pathway with other pathways that are known to regulate these functions. For example, the insulin like growth factor-1 (IGF-1) pathway falls under the numerous genes affected by the AR-pathway (Schayek et al., 2010). Some of the SMAD and ID proteins involved in the transforming growth factor-beta (TGF $\beta$ ) pathway are also regulated. Androgens negatively regulate the expression of SMAD1, 3, 6 and 7, while ID3 expression is markedly increased (Ngan et al., 2009). Some of the forkhead box (FOX) family of transcription factors which are important in cell survival are differentially regulated by AR activity (Takayama et al., 2008). Furthermore some of the FOX genes can influence AR expression and activity itself. For example, FOXP1 has been shown to negatively regulate AR expression (Takayama et al., 2008). Cyclin D, cdc6 and genes such as UBEC2 are some of the genes regulated by the androgenic signalling that control cell cycle checkpoints of PCa cells. In addition, the AR signalling can regulate PCa cells apoptosis by regulation of anti-apoptotic molecules such as FLIP (Gao et al., 2005; Raclaw et al., 2008).

Androgens also control the lipid and steroid metabolic pathways that are important in providing energy to cells undergoing proliferation. Sterol regulatory element-binding proteins (SREBPs), which are responsible for activation of numerous enzymes involved in cholesterol processes such as HMG-CoA, acyl CoA:cholesterol acyltransferase (ACAT) are regulated by AR (Locke et al., 2008; Leon et al., 2010).

Recently, reports are exploring the impact of AR signalling in the formation of fusion protein arrangements. Androgenic signalling has demonstrated the ability to promote interactions of genomic regions and DNA breaks (Lin et al., 2009).

MicroRNA profiling in the parental hormone naive cell line LNCaP in comparison to castrate resistant LNCaP- derived cell line has identified 17 differentially expressed miRNAs between the two cells lines (deVere White et al., 2009). In the same study, miR-125b was shown to be highly expressed in AR expressing cell lines such as CWR22R, PC-346C, LNCaP, cds1 and cds2 cells when in AR negative cell lines (DU145, PC3, pRNS-1-1 and RWPE-1) its expression was diminished. These findings suggest that miR-125b may be related to prostatic tumorigenesis and androgen independent (AI) growth, and the AR may regulate the expression of this miRNA in CaP cells. That notion is further supported by the altered expression of miR-125b upon anti-androgen treatment (deVere White et al., 2009). There are numerous evidence demonstrating the ability of PCa cells to respond to lower levels of androgens due to overexpression of AR protein (Chen et al., 2008). The AR is upregulated in most CRPCs, of which only 10-20\% exhibit amplification of the AR gene 
(Edwards et al., 2003), indicating that increased AR expression in CRPC may result from factors other than gene amplification such as increased transcription from endogenous promoters or from stabilisation of mRNA (Lammond and Tindall, 2010; Shiota et al., 2011).

Depletion of androgens during PCa treatment can lead to structural and functional changes of AR in the PCa cells in order to adjust and survive in the hormone depleted environment (Pienta et al., 2006). Somatic mutations in the ligand binding pocket of the ligand binding domain (LBD) of AR are a common feature amongst castrate resistant and metastatic prostate tumours, with more than $50 \%$ of tumors presented with this type of mutations. AR mutations can alter the binding specificity of AR. For example, the missense mutation of threonine to alanine at amino acid 877 (T877A) leads to an increase in the type of ligands that can bind AR; with estrogens and progesterone having a similar binding affinity as androgens in this instance (Montgomery et al., 2001; Han et al., 2005). Recently seven more variants have been discovered to be over-expressed in castrate resistant PCa (CRPC). Two of these, AR-V1 and AR-V7 that were studied in full detail, were shown to possess premature termination codons. High expressions of both variants correlated with poor prognosis of patients at CRPC (Hu et al., 2009). The splicing variant AR23, that was recently detected in a patient with metastatic CRPC has impaired nuclear localisation and increases androgen signalling only in the presence of endogenous wildtype AR (Jagla et al., 2007). Furthermore this variant has the ability to regulate other signalling pathways such as increasing the transcriptional activity of nuclear factor kappa $\mathrm{B}(\mathrm{NF \kappa B})$ and decreasing the activity of activator protein-1 (AP-1). The presence of AR variants have been investigated in CRPC cell lines also. AR3, AR4 and AR5 variants were identified in C-821, CWR-R1 and CWR22Rv1 cell lines, with AR3 being the most abundant variant in these cell lines. AR3 showed both cytoplasmic and nuclear localisation of AR, however, AR3 function, activity and expression was not affected by the presence of androgens or anti-androgens demonstrating the androgen independence of PCa cells in CRPC state. Furthermore, the same study has pinpointed Akt- 1 through a microarray analysis, as the key difference between the AR and AR3 signalling pathway to drive growth of CRPC cells (Guo et al. 2009). Another AR mutation has been identified in the CRPC cell line CWR22Rv1 that was absent in the parental hormone naive mimicking cell line CWR22. This mutation resulted in the generation of AR protein fragments; one characterised by a duplication of exon 3 of AR leading to ARex3dup protein with molecular weight of $114 \mathrm{kDa}$, and a second protein $\mathrm{AR} \triangle \mathrm{LBD}$ with a truncated ligand binding domain and a lower molecular weight of $75-80 \mathrm{kDa}$ (Dehm et al. 2008). Both variants have distinct roles in the hormone naive and CRPC states; ARex3dup protein affects the growth of hormone naive cells while AR $\triangle \mathrm{LBD}$ protein affects the growth of castrate resistant cells (Tepper et al., 2002).

\section{Heat shock proteins}

Heat shock proteins (Hsps) are a superfamily of proteins produced in cells in response to environmental stresses and in particular heat. It is now well established that Hsp70 and Hsp90 are bound to the AR when it is held in its inactive form in the cytoplasm. The function of the Hsps is to stabilise the receptor and protect it from protelytic degradation. However when androgens bind to the AR, Hsp 70 and 90 dissociate, allowing the AR to 
form homodimers and transolcate to the nucleus. The first evidence that Hsps were involved in PCa was obtained almost two decades ago from the direct interaction of the Hsp members Hsp90, Hsp70 and Hsp56 with AR (Veldscholte et al., 1992). Furthermore, this interaction has been recently verified in a heterologous AR expression system in the 293HEK cell line. This recapitulates AR SHR activity in PCa cells that identified these Hsps as putative AR-binding proteins in the cytosolic extracts using the ICAT method (Jasavala et al., 2007).

Hsps have been implicated in apoptosis and survival of PCa cells as well as response to chemotherapeutic treatment. The role of Hsps in these cell processes differs depending on the Hsp member involved. The anti-apoptotic role of Hsp70 in PCa, which is known to bind to the $\mathrm{AR}$ in the inactive state, was demonstrated in vitro by direct transfection of adenoviral Ad.asHsp70 in PCa cells such as PC-3 and DU145 cells. The result was impressive, leading to cell death of tumorigenic cells within three to five days post-transfection (Nylandsted et al., 2000). Increase of Hsp27 and Hsp72 have also been implicated in resistance to apoptotic signals in vitro (Gibbons et al., 2000; Garrido et al., 2003). Hsp27 modulates apoptosis through prevention of the apoptosome formation and activation of caspases through direct sequestration of cytochrome $\mathrm{c}$ released from the mitochondria into the cytosol or cytochrome c-mediated caspase activation by sequestering both pro-caspase- 3 and cytochrome c (Bruye et al., 2000, Paul et al., 2000). Also, Hsp27 at high levels may prevent the caspase- 8 activation of the pro-apoptotic Bid protein, a member Bcl-2 family (Concannon et al., 2000). Results from a tissue microarray study on changes in Hsp27 protein expression in 232 specimens from hormone naive and posthormone-treated cancers showed that Hsp27 expression was low or absent in untreated human PCas but increased 4 weeks after beginning androgen-ablation to become uniformly highly expressed in AI tumors (Rocchi et al., 2004). The same group has evaluated the functional relevance of Hsp27 changes in AI progression providing a mechanism by which castration-induced changes in Hsp27 expression serves as an upstream regulator of Stat3 activity (Rocchi et al., 2005). The correlation of the expression of Hsp27, Hsp70 and Hsp90 has also been evaluated in relation to clinicopathological outcomes in patients undergoing radical prostatectomy (Kurashami et al., 2007). Only Hsp27 expression is significantly associated with pathological stage, Gleason score, surgical margin status, lymph node metastasis and tumor volume as well as cell proliferative activity.

\section{Src expression}

The Src family encompasses nine non-receptor protein kinases: Src, Fyn, Yes, Blk, Yrk, Fgr, Hck, Lck and Lyn with similar structural features. Numerous in vitro studies have shown the significance of Src in the development of PCa and its progression to a hormoneindependent state (Slack et al., 2001; Recchia et al., 2003; Nam et al., 2005). In addition, the clinical association between Src family kinase (SFK) activity and PCa patient survival suggests that SFK activity is up-regulated in a subgroup of CRPC patients (Tatarov et al., 2009). Furthermore, the same study suggested that an increase in SFK activity in CRPC patients may result in higher likelihood of metastatic disease, which could potentially contribute to the reduction in survival.

Extensive cross-talk and co-regulation are two features of the SFK member action. Moreover, the Src proline-rich sequences of AR have the affinity for SH3 domain of Src, so 
that the resulting complexes release Src intramolecular constrains activating the tyrosine kinase. Androgen stimulation acts as a trigger for the AR-Src complex formation, which is followed by activation of Src/Raf-1/Erk-2 pathway and, as a result, increases in PCa cell proliferation. Application of androgen antagonists, expression of Src lacking SH3 domain and treatment with Src inhibitor prevented androgen stimulated S-phase entry (Migliaccio et al., 2000). A significant correlation between AR and Src activation in human prostate tumours has been found with proposed tyrosine Y534 as a Src-specific phosphorylation site. Introduction of a dominant negative mutant of Src kinase prevents AR activation and its translocation to the nucleus (Lee et al., 2001). These findings suggest that androgen deprivation therapy may result in Src activation by growth factors, which can then stimulate AR activity as a potential hormone escape mechanism (Guo et al., 2006). Epidermal growth factor (EGF) acting through epidermal growth factor receptor (EGFR) has been shown to activate Src in PCa cells, experiencing acute androgen withdrawal by triggering AR-Src complex formation. Resulting DNA synthesis and cytoskeletal changes were abrogated by treatment with androgen antagonists, suggesting that the relationship between AR and Src play an important role in PCa cells biology (Migliaccio et al., 2005; Hitosugi et al., 2007). Androgen independent growth and cell migration stimulated by Interleukin-8 (IL-8) signalling may involve transactivation of AR by Src as application of Src inhibitors and AR antagonists significantly inhibited these biological processes (Lee et al., 2004). Interaction between IGF system and steroid receptor signalling is thought to play an important role in prostatic carcinogenesis, although the precise mechanism of action is not completely understood $(129 ; 130)$. Androgens have been shown to up-regulate IGF-1R expression and IGF-1-induced Src/MAPK signalling in AR-positive prostate cancer cells (Pandini et al., 2005). Activation of oestrogen receptor $\beta$ (ER $\beta)$, known to form complexes with Src and AR in prostate cancer cells, can result in similar effect on IGF-1R expression and activation (Pandini et al., 2007).

SFK members are involved in the regulation of focal adhesions, thus playing a key role in the regulation of cell motility, migration and invasion. Activation of guanosine phosphate binding protein coupled receptors (GPCRs) results in complex formation between Src and FAK in focal adhesions, whereas Lyn is thought to inhibit these cellular functions by acting as an intermediary between NEP and p85 subunit of PI3-K, preventing association of PI3-K and FAK (Sumitomo et al., 2000). Src is thought to be the main factor in tyrosine phosphorylation of ezrin, an adaptor protein which is implicated in invasion, migration and is important for the development of metastatic PCa (Curto and McClutchey, 2004). Application of Src inhibitor PP2 reduced ezrin phosphorylation and decreased invasive capacity of androgen stimulated PCa cells (Chuan et al., 2006). Growth factors released into the bone microenvironment, including transforming growth factor $\beta$ (TGF $\beta$ ), fibroblast growth factor (FGF), IGF, and platelet derived growth factor (PDGF) stimulate Src-mediated osteoclast activity, leading to further bone destruction and release of biologically active substances from the bone matrix, stimulating the proliferation and migration of tumour cells (Araujo and Logothetis, 2009; Edwards, 2010).

\section{PI3K signalling}

Several key components of the PI3K/Akt cascade have been implemented in prostate carcinogenesis and castration resistance. PI3K inhibition has been studied in vitro for some 
time and evidence of its key role in carcinogenesis continue to emerge. Genetic analysis of high Gleason grade PCas revealed 3\% of patients had PIK3CA mutation and 13\% had PIK3CA amplification (Sun et al., 2009). Up regulation of PI3K signalling may also be due to overexpression of receptor tyrosine kinases (RTKs) which have been previously reported to be overexpressed in prostate tumours and cell lines (Grasso et al., 1997; Yeh et al., 1999; Barlett et al., 2005). PI3K has shown to be an important signalling molecule and key survival factor involved in PCa proliferation and invasion. Studies have reported that treatment of LNCaP, PC-3 and DU145 with PI3K pharmacological inhibitor, LY294002, potently suppresses the invasive properties in each of these cell lines and restoration of the PTEN gene to highly invasive prostate cancer PC-3 cells or expression of a dominant negative version of Akt also significantly inhibites invasion and down regulates protein expression of urokinase type plasminogen activator (uPA) and matrix metalloproteinase (MMP)-9, markers for cell invasion. Increased levels of PI3K (p110) and regulatory (p85) and Akt were also observed in these cell lines (Shukla et al., 2007).

A somatic mutation in AKT1 (E17K) has been detected in numerous cancers including prostate (Bleeker et al., 2008; Boorman et al., 2010). The E17K substitution leads to a PI3K independent activation of AKT1. In PCa, AKT1 mutation was reported to have a prevalence of just $1.4 \%$ and the mutation seemed to be associated with favourable clinical outcome and was not associated with a specific tumour growth pattern (Boormans et al., 2010). Overexpression of Akt in PCa is hypothesised to be due to defective PTEN gene as discussed below. Prostate tumours are reported to have significantly higher Akt expression than BPH (Liao et al., 2003), and only 10\% of well-differentiated prostate tumours strongly express pAkt compared to $92 \%$ of poorly differentiated tumours (Malik et al., 2002; Ayala et al., 2004). Additionally, in hormone-naive tumours Akt1 and Akt2 expression has been associated with shorter time to biochemical relapse; and amplification was observed in castrate resistant tumours (Kirkegaard et al., 2010). In addition phosphorylation of Akt increases with the development of castrate resistant disease and is associated with reduced disease specific survival (McCall et al. 2008; Edwards et al., 2006). Loss of PTEN has been associated with advanced prostate cancer (Gray et al., 1998) and loss of PTEN expression is associated with increased risk of recurrence in human tumours (McMennin et al., 1999, McCall et al., 2008).

PCa cell lines that have been cultured from metastatic sites such as the lymph nodes (LNCaP) or brain metastasis (PC3) have highly active PI3K/Akt signalling and PTEN deletion (Davies et al., 1999; Murillo et al., 2001) The magnitude of loss of function of PTEN is best described in both localised and metastatic PCas and includes homozygous deletions, loss of heterozygosity (LOH) and inactivating mutations (Sarker et al., 2009). The reported frequency and mode of inactivation at different stages of PCa varies. Homozygous deletions of PTEN have been detected in up to $15 \%$ of locally confined PCa and up to $30 \%$ in metastatic cases (Verhagen et al., 2006; Yoshimoto et al., 2007). Heterozygous loss has been reported in $13 \%$ of locally confined prostate cancers and up to $39 \%$ in metastatic cases (Samuels et al., 2004; Verhagen et al., 2006; Yoshimoto et al., 2007). PTEN mutation has been associated with $5-27 \%$ of localised and $30-60 \%$ of metastatic prostate tumours (Feiloter et al., 1998; Suzuki et al., 1998) In addition, loss of PTEN expression is associated with disease progression and increased risk of recurrence (Fenci et al., 2002) although substantial heterogeneity has been observed between different metastatic sites within the same patients (Suzuki et al., 1998). 
Many oncoproteins and tumor suppressors intersect in the PI3K cascade, regulating cellular functions at the interface of signal transduction and classical metabolic regulation. This careful balance is altered in human cancer by a variety of activating and inactivating mechanisms that target both Akt and interrelated proteins. Numerous studies have suggested that PI3K signalling enhances its oncogenic signal through interaction with other signalling networks such as the transcription factor Nuclear factor Kappa B (NFKB) (Romashkova and Makarov, 1999). Recent reports suggest that suppression of NFkB activity by inhibitory kappa B (IKB) superepressor induces a strong and selective resistance to PI3K or Akt induced oncogenic transformation which suggests an essential role for $\mathrm{NF \kappa B}$ in the transforming mechanisms induced by this signalling cascade (Bai et al., 2009).

\section{NFKB signalling}

NFkB has been shown to be constitutively activated in PCa cells. Evidence on the direct involvement of NFKB in the regulation of angiogenesis and metastasis of PCa cells have already been obtained. Suppression of NFKB activity in human PCa cells by inhibitory kappa B alpha (IKBa) mutation transfection inhibits their tumorigenic and metastatic properties in nude mice by suppressing angiogenesis and invasion. In the same experiments, IKBaM transfectionblocked NFKB activity was associated with downregulation of several angiogenic genes such as vascular endothelial growth factor (VEGF), interleukin 8 (IL-8) and matrix metalloprotease9 (MMP-9) in cultured cells and in cells implanted into the prostate gland of nude mice. The decreased expression of VEGF, IL-8 and MMP-9 in vivo directly correlated with decreased neovascularization and production of lymph node metastasis. In addition, direct clinical correlations of the expression levels the angiogenic genes, including VEGF, basic fibroblast growth factor (Bfgf), IL-8 and MMP-2 and MMP-9 with the metastatic potential of PCa cells has already been established (Huang et al., 2002;Andela et al., 2003).

The association between steroid hormone receptor expression and NFKB activation has been of substantial interest in prostate cancer. Prominent constitutive NFkB has been observed in the prostate cancer cell lines PC-3 and DU-145 which lack AR expression however, only very low levels of NFKB were seen in the AR positive cell line LNCaP (Suh et al., 2002). Moreover, a markedly higher NFKB activity in an androgen independent prostate cancer xenograft model than in its androgen dependent counterpart (Chen et al., 2002). Here NFkB activated expression of AR regulated gene PSA. This data may suggest that either the presence of AR actually inhibits NFKB activity in prostate cancer or alternatively that constitutive activation of NFKB may correlate with AR loss, which in turn may contribute to compensatory cellular changes, allowing cell survival and growth in the absence of AR activation.

NFKB has been implicated with PCa progression via two mechanisms, promotion of metastases via MMP-9 expression or promotion of androgen independence via an as yet unknown mechanism. It was suggested that the absence of PTEN might contribute to constitutive activation of $\mathrm{NFKB}$ induced by PI3K/Akt pathway. However no direct correlation has been observed in prostate cancer cell lines.

\section{Bcl-2 signalling}

Bcl-2 family plays a central role in the mitochondrial pathway of apoptosis by regulation of the integrity of the outer membranes of mitochondria. Members of this family have different 
role in apoptosis; $\mathrm{Bcl}-2, \mathrm{Bcl}-\mathrm{xL}, \mathrm{Bcl}-\mathrm{w}, \mathrm{A} 1$, and $\mathrm{Mcl}-1$ members are considered as antiapoptotic molecules while Bax, Bak, and Bok have pro-apoptotic functions and Bad, Bim, Bid, Puma, and Noxa control the activation of pro-apoptotic proteins.

In PCa, Bcl-2 expression is correlated with a higher Gleason score and pT category and is lower in localized PCa compared with HRPC change to CRPC (McDonnell et al., 1992; Apakama et al., 1992; Bubendorf et al., 1996). It has been reported that high expression of Bcl-2 may enable the PCa cells to survive in an androgen-deprived environment, and to confer resistance to anti-androgen therapy (McDonnell et al., 1992). On the other hand, Bak and Bax expression is significantly higher in localized PCa than in HRPC. In addition, decreased Bax expression is associated with an increased pre-operative PSA level in localized PCa and early disease progression in HRPC (Yoshino et al., 2006). These findings suggest that differential regulation of anti-apoptotic Bcl-2 protein and proapoptotic proteins may be involved with the processes controlling the development of HRPC as well as disease progression in PCa (Yoshino et al., 2006). In vitro, Bax and Bcl-X overexpression resulted in apoptotic cell death in PCa cells such as PC3 and DU145, which are known to offer resistance to a variety of chemical proapoptotic agents as well as LNCaP cells (Marcelli et al., 2000; Li et al., 2001; Castilla et al., 2006). Bcl-X expression is observed in all tumours and was generally stronger in high grade primary tumors (grade 8 to 10) and metastases compared with PIN and low grade neoplasms $(\mathrm{P}<0.0001)$ (Krajewska M et al., 1996; Castilla et al., 2006). On the other hand, a recent study in a 58 patient cohort of PCa patients aith matched tissue from androgen-dependent to CRPC tumours, showed that there was a trend with improved overall survival in patients with increased Bad expression at diagnosis.

In addition, there were trends towards a decrease in Bad and Bax expression with disease progression (Teo et al., 2007). These results might signify that Bad expression may represent a possible positive prognostic marker and useful therapeutic target in HRPC management in the future.

\section{IL-6R/STAT3}

The IL-6R/gp130/JAK/STAT3 pathway is also implicated in the development of PCa. It is known that circulating levels of IL-6 in sera of patients with CRPC are elevated in comparison to hormone naive patients (Hobisch et al., 1998; Drachenberg et al., 1999). The initial hypothesis of cross-talk between IL- 6 and the AR, by measuring the effects of IL-6 on AR transcriptional activity, was investigated in two cell lines, DU-145 which transiently expresses the AR and $\mathrm{LNCaP}$ which contains a promiscuous mutated AR. In both cell lines IL- 6 activated the AR in a ligand-independent and synergistic manner with low concentrations of a synthetic androgen (methyltrienolone) (Hobisch et al., 1998). Later, Yang et al (2003) was to demonstrate that IL-6, enhanced AR transactivation via IL6R/STAT3 pathway. Lee et al (2004) observed that androgen sensitive LNCaP cells in the presence of IL-6 were protected from apoptosis when deprived of androgen. However, the anti-apoptotic activity of IL- 6 was prevented by the expression of a dominant-negative STAT3 mutant, STAT3F. Furthermore, androgen deprivation induced LNCaP cell death which was antagonized by ectopic expression of a constitutively active STAT3 (Lee et al., 2004). DeMiguel et al (2002) has demonstrated that constitutive activation of STAT3 is associated with increased cell growth and prolonged survival in androgen sensitive LNCaP cells. The study was extended to involve in vivo work using both intact and 
castrated nude male mice. Activation of STAT3 resulted in an increase in tumour growth in both groups of mice. This study shows that STAT3 can enhance the growth of hormone sensitive tumour even in low circulating androgen conditions in vivo. More in vivo work demonstrated that constitutive activation of STAT3 was found in $82 \%$ of human prostate tumours as compared with matched adjacent non-tumour prostate tissue in radical prostatectomy samples (Edwards et al., 2005). Furthermore higher levels of STAT3 activation correlated with a more aggressive tumour or a higher Gleason score. In addition to this, three prostate cancer cell lines, DU145, PC3 and LNCaP cells were examined all of which displayed constitutive activation of STAT3, though substantially lower levels of STAT3 activation was observed in hormone sensitive LNCaP cells. This further supports the fact that STAT3 activation is involved in the progression of prostate cancer. The fact that activated STAT3 is found in tumour and not around its normal margins of prostatectomy samples was further supported by Barton et al (2004). In addition they also showed that directly inhibiting STAT3 either using antisense STAT3 oligonucleotides or by transfecting cells with a dominant negative (DN) STAT3 plasmid, resulted in apoptosis. Cell lines used were NRP-154 and DU145 and apoptosis was seen in both lines when inhibition of STAT3 was performed. From these data the authors conclude that STAT3 specific inhibitors could be used in treating CRPC. Similar conclusions were drawn by (Tam et al, 2007) who reported that cytoplasmic pSTAT3Tyr 705 expression is associated with time to death from hormone relapse and disease specific survival of the prostate cancer patients that develop castrate resistant disease.

\section{Mitogen activated protein (MAP) kinase pathway}

Alterations to members of the Raf/MAP kinase pathway have been linked with the progression of several solid tumours including prostate cancer (Weinstein-Oppenheimer et al., 2000). Most solid tumours demonstrate a link between Ras mutation and MAP Kinase activation (Edwards et al., 2004). Mutated Ras has been linked with increased levels of activated MAP Kinase and the development of androgen-independent growth in LNCaP cells (Bakin et al., 2003; Edwards et al., 2004). Activated MAP Kinase and MEK are also differentially expressed during the progression of prostate cancer in a transgenic mouse model (Uzgare et al., 2003-as referenced in Edwards et al., 2004). Raf and MEK are known to be expressed in both non-metastatic and metastatic prostate cancer cells (Weinstein-Oppenheimer et al., 2000; Fu et al., 2003). Increased MAP Kinase activity is known to be elevated in androgen insensitive cell-lines and in clinical CRPC (AbreuMartin et al., 1999; Gioeli et al., 1999). Recently increasing levels of Raf-1 and/or MAPK correlated with a more rapid biochemical relapse and rapid decline into CRPC, thus negatively impacting on survival time (Mukherjee et al., 2011). Intriguingly, the constitutively active form of MAP Kinase also induces Raf-1 activation in cell-line studies, forming the positive feedback loop required for chronic autocrine stimulation (Allessandrini et al., 1997; Weinstein-Oppenheimer et al., 2000). MAP Kinase has also been demonstrated to increase transcription of androgen-dependent genes, independently of androgens, via either direct or indirect phosphorylation of the AR (Abreu-Martin et al., 1999; Bakin et al., 2003; Franco et al., 2003). MAP Kinase is known to activate the AR N terminal domain (NTD) by phosphorylation of the serine 515 site independently of androgen (Yeh et al. 1999; Rochette-Egly, 2003). Inhibition of MAP Kinase in cell-line studies is known to abrogate IL-6 and PKA activation of the AR, suggesting a crucial role 
in the convergence of both pathways towards the AR NTD (Ueda et al., 2002). Hydroxyflutamide has been shown to activate the Raf/MAP Kinase pathway independently stimulating cell proliferation, possibly via a member of the EGFR receptor family (Lee et al., 2002). Activation of the pathway has therefore been linked with the pathogenesis of the androgen-withdrawal syndrome, by stimulating androgenindependent cell growth in response to antiandrogens. Data has also revealed increased activation of the MAP Kinase pathway in prostate cancer in patients with tumour progression (Gioeli et al., 1999; Lee et al. 2002). Taken together, the MAP Kinase pathway appears to play a crucial role in cross-talking with the AR-signalling pathway, modulating its response to ligands. It may also function as a surrogate for ligand-activation during androgen withdrawal, resulting in the progression to CRPC.

\section{Human epidermal growth factor receptor (her) signalling}

The Human Epidermal Growth Factor Receptor (HER) family consists of 4 transmembrane glycoprotein receptor molecules and their variants; Epidermal Growth Factor Receptor (EGFR also known as HER1 and ErbB1), HER2 (ErbB2), HER3 (ErbB3) and HER4 (ErbB4). The HER family members are all differentially expressed in malignant compared to benign prostatic tissue. Great variability of EGFR has been reported amongst studies, with 17-100\% detactable levels observed (Di Lorenzo et al., 2002) which has been attributed mainly in PCa disease heterogeneity amongst tissue specimens and variation in IHC technique procedures (Hernes et al., 2004). EGFR overexpression both at the protein and transcript level has been reported in metastatic PCa in numerous studies (Kumar et al., 1996, Kim et al., 1999). Furthermore, the expression of EGFR variant EGFRvII has only been detected in PCa cells and not in benign prostate tissue. In addition EGFRvII expression is greater in CRPC samples compared to hormone naive tissue (Olepade and Oleopa, 2001). Contradictory is also the expression of HER2 in studies in patient tissue; some studies have noted greater expression of HER2 in PCa than benign tissue (Hernes et al., 2004; Okegawa et al., 2006) while others demonstrated no significant difference between the two states (Mellon et al., 1992). In general, HER2 expression in PCa is lower than other tumor types (Edwards, 2003). Furthermore, HER2 gene amplification is not a feature of the transition of hormone naive PCa to CRPC (Bartlett et al., 2005). HER3 is consistently expressed in PCa tissue, however, only nuclear expression and not cytoplasmic is significantly different from benign tissue (Koumakpayi et al., 2006). On the other hand, HER4 is expressed at low levels in PCa tissue and its expression in CRPC samples may offer up to 2 years survival (Hernes et al., 2004). This is contradictory to HER1-3 expression which is associated with worse prognosis. Heregulins are highly expressed in benign prostate tissue compared to malignant (prostatectomy derived PCa) (Lyne et al., 1998). This may indicate that HRGs may act as tumor suppressors and its loss might signify an early stage in PCa oncogenesis.

HER role in prostate carcinogenesis relies in cross-talk interactions with other pathways. EGFR member can cross-talk with the signalling pathways of P13K/Akt, MAP kinase and PKC to increase growth, modulate cell cycle progression, cell motility and angiogenesis of $\mathrm{CaP}$ oncogenesis (Mimeault et al., 2003). Overexpression of the EGFR-HER2 heterodimer in comparison to other HER dimers is considered an alternative mechanism of HERinduced carcinogenesis (Xia et al., 1999). EGFR activity has been implicated in hormone escape. EGFR signalling has been shown to activate AR in the absence of adrogenic 
stimulation (Mimeault, 2003). Cross-talk between HER2 and AR pathways is also apparent (Mellinghoff et al., 2004; Yeh et al., 1999). HER2 and HER3 expression, stimulated by HRG, have also been shown to increase AR transactivation and tumour proliferation in a recurrent CaP cell line in the absence of androgen (Gregory et al., 2005). Overexpression of HER2 has been shown to be induced by low androgen environments in vitro and in vivo (Berger et al., 2006). Androgen independent AR transactivation can be induced by spontaneous HER2 homodimerisation in the presence of extreme overexpression of HER2 (Wen et al., 2000). In vitro, the Q646C constitutively active HER4 mutant inhibits formation of colonies in DU-145 and PC-3 CaP cell lines suggesting that the HER4 signalling is coupled to PCa cell growth arrest and tumor suppression (Williams et al., 2003).

\section{Fibroblast growth factor (FGF) receptor signalling}

FGF functions are mediated through high ligand-specific affinity receptor signalling. FGF receptor overexpression has been evident in malignant PCa biopsies of patients. In particular, FGFR1 and FGFR4 receptor expression at protein and transcript level are significantly upregulated compared to benign prostates (Sahadevan et al., 2007). Furthermore, FGFR1 is involved in PCa initiation (Acevedo et al., 2007) and promotes tumour progression (Feng et al. 1997). Transgenic models that express constitutively active FGFR-1 in the prostate epithelium develop hyperplasia and PIN (Wang et al. 2002, 2004a) and increased expression accelerates the appearance of this phenotype (Jin et al. 2003; Kwabi-Addo et al., 2004). The role of FGFR2 in prostate cancer is dependent on the expression of its specific isoform (Kwabi-Addo et al., 2001). More specifically, increased expression of FGFR2IIIc isoform and not of FGFR2IIIb was observed in only in a subset of PCa tissue compared to normal epithelial cells. No significant change in the levels of FGFR3 expression and cellular localisation is observed in both benign prostatic hyperplasia (BPH) and PCa tissue (Gowardhan et al., 2005). Increased FGFR4 expression and the germline FGFR4 Gly388Arg polymorphism is associated with adverse survival of patients with PCa (Wang et al. 2004; Gowardhan et al., 2005; Murphy et al., 2010). Moreover, the presence of the FGFR4 GlyArg388 polymorphism is correlated with the occurrence of pelvic lymph node metastasis and PSA recurrence in men undergoing radical prostatectomy. Expression of the FGFR-4 Arg388 in immortalized PCa epithelial cells results in increased cell motility and invasion and upregulation of the urokinase-type plasminogen activator receptor (uPAR), which is known to promote invasion and metastasis (Sidenius \& Blasi, 2003; KwabiAddo et al., 2004).

In PCa, upregulation of some ligands of the FGF system has also been reported; FGF1, FGF2, FGF6, FGF8, FGF10 and FGF17 mainly used as autocrine or paracrine factors for PCa cells (Heer et al., 2004; Kwabi et al., 2004). FGF1 is known to be expressed in more than $80 \%$ of PCa (Dorkins et al., 1999) and be increased in PIN. FGF1 was shown to induce the expression of matrix metalloproteinase MT1-MMP which is also overexpressed in PIN and invasive cancers and might provide a link to the role of FGF1 in the progression of PCa (Udayakumar et al., 2004). FGF2 expression is altered during the progression of PCa; evidence shows that paracrine stromal expression can be observed during early stages of PCa which eventually switches to autocrine expression by epithelial cells (Dorkin et al., 1999; Girri and Ittmann, 2001). FGF1 and FGF2 regulate angiogenesis. In particular, expression of FGF2 in PCa cells and stromal cells can induce tumour vasculature 
formation (Powers et al., 2000; Kwabi-Addo et al., 2004). FGF6 is expressed by normal prostatic basal cells in extremely small amounts, and expression in basal cells is markedly increased in PIN lesions. The acquisition of FGF6 expression by the prostate cancers implies but does not prove that it may play a role in cancer cell proliferation or perhaps in other aspects of tumor progression (Ropiquet et al., 2000). The role of FGF7 still remains unclear although it was one of the first factors shown to regulate AR transcription in PCa cells, along with EGF and IGF-I (Culig et al.,1994). Recent evidence support the role of paracrine mesenchymal FGF10 in driving tumourgenesis as enhanced expression of mesenchymal FGF10 was sufficient for histologic transformation of the adjacent prostate epithelium in CB.17SCID/SCID mice (Memarzadeh et al., 2007). FGFs play an important role in all stages of bone formation. Thus, it is not surprising that some FGF members have been linked with bone metastasis of PCa. FGF8 secreted by cancer cells regulates osteoblast differentiation by enhancing osteoprogenitor cell proliferation and their osteogenic capacity (Valta et al., 2006). Moreover, FGF8 in particular is expressed highly in PCa bone metastasis and was recently shown to increase the growth of intratibial PC3 tumors in nude mice used as an experimental model for PCa bone metastasis (Valta et al., 2008). FGF8 can also induce FGF17 expression which has also been associated with bone metastasis (Heer et al., 2004).

\section{Insulin growth factor receptor (igfr) signalling}

The insulin-like growth factor (IGF) system, is composed of the receptors IGFR-IR, IGFR-IIR, insulin receptor (IR), numerous atypical receptors, two ligands (IGF-I and IGF-II), and six binding proteins (IGFBP-1 to -6) (Nakae et al., 2001). Involvement of the IGF system in the progression of hormone naïve PCa to CRPC and metastasis of PCa tumour has had a long standing role, and along with androgens and EGF, IGFs represent another important class of mitogens in PCa. Early in vitro work has shown that treatment with IGF-I and IGF-II can increase the proliferation of PCa DU145 cells (Connolly and Rose, 1994). However, in LNCaP cells, IGF-I alone was unable to increase cell growth in growth factor free conditions, revealing the need of IGF signalling for co-operation with other factors in order to promote tumour cell growth (Ngo et al., 2003). Although most of the members of the IGF system are expressed in PCa patients the results from numerous studies are fairly contradictory. Studies on the IGF-I serum levels and PCa risk have shown mixed results with some studies showing a positive correlation while others showing no or inverse correlation. Furthermore similar associations were produced for IGFBP3 and PCa. A large study from the Cancer Research UK Epidemiology Unit in 2007 examining 630 specimens from PCa patients at diagnosis and 630 matched control samples, did not identify a strong correlation between serum IGF-I neither IGFBP3 and PCa risk and only a small increase in risk was noted for advanced stage disease.

Significant interactions of IGF-I have been reported with AR, depicting a significant involvement of this pathway in CRPC. In vitro experiments in M12AR cells showed that IGF-I enhances nuclear translocation of AR in the absence of any androgenic signal and this effect can be inversed by an IGF-IR inhibitory antibody (Wu et al., 2006). In vitro studies have demonstrated that IGF-1R downstream signalling via MAPK pathway may promote proliferation of prostate cancer cells whereas involvement of PI3K-AKT pathway is required to inhibit apoptosis (Genningens et al., 2006). 
IGF-I plays an important role in PCa bone metastasis. IGF-I can cross-talk with the NFאB pathway by direct upregulation of RANK ligand and osteoblasts and binding to RANK. Activation of NFKB leads to osteoclast synthesis and osteoprotegerin (OPG) thus driving bone formation and resorption (Fizzazi et al., 2003).

\section{Conclusion}

The signalling pathways involved in the initiation and progression of $\mathrm{PCa}$ are complex and require further investigation. However in this chapter we have attempted to elucidate which receptors (HER, FGFR and IGFR) and intracellular signalling pathways play major roles in prostate cancer. In addtion, we also demonstrate that the AR has a central role to play in both hormone naïve and castrate resistant disease, and it is only by unravelling the interactions between cell surface receptors, intracellular signalling and steroid receptors that we are going to move forward with a targeted personalised approach to treatment of PCa.

\section{References}

Abreu-Martin, M.T., Chari, A., Palladino, A.A., et al. (1999) Mitogen-activated protein kinase kinase kinase 1 activates androgen receptor-dependent transcription and apoptosis in prostate cancer. Mol Cell Biol, Vol.19, pp. 5143- 5154.

Acevedo, V.D., Gangula, R.D., Freeman, K.W., et al. (2007) Inducible FGFR-1 activation leads to irreversible prostate adenocarcinoma and an epithelial-to-mesenchymal transition. Cancer Cell, Vol.12, pp.559-571.

Alessandrini, A., Chiaur, D.S., Pagano, M. (1997) Regulation of the cyclindependent kinase inhibitor p27 by degradation and phosphorylation. Leukemia, Vol.11, pp.342 - 345.

Andela, V.B., Gordon, A.H., Zotalis, G., et al. (2003) NF kappa B: A pivotal transcription factor in prostate cancer metastasis to bone. Clinical Orthopaedics and Related Research, Vol.415, pp.S75-S85.

Apakama, I., Robinson, M.C., Walter, N.M., et al. (1996) Bcl-2 overexpression combined with p53 protein accumulation correlates with hormone-refractory prostate cancer. Br J Cancer, Vol.74, pp.1258-62.

Araujo, J., Logothetis, C. (2009) Targeting Src signaling in metastatic bone disease. Int J Cancer, Vol.124, pp.1-6.

Ayala, G., Thompson, T., Yang, G., et al. (2004) High Levels of Phosphorylated Form of Akt-1 in Prostate Cancer and Non-Neoplastic 208 Prostate Tissues Are Strong Predictors of Biochemical Recurrence. Clin Cancer Res, Vol. 10, pp. 6572-6578.

Bai, D., Ueno, L., Vogt, P.K. (2009) Akt-mediated regulation of NFkappaB and the essentialness of NFkappaB for the oncogenicity of PI3K and Akt. Int J Cancer, Vol. 125, pp.2863-2870.

Bakin, R.E., Gioeli, D., Sikes, R.A., et al. (2003) Constitutive activation of the Ras/mitogenactivated protein kinase signaling pathway promotes androgen hypersensitivity in LNCaP prostate cancer cells. Cancer Res, Vol.63, pp.1981- 1989.

Bartlett, J.M., Brawley, D., Grigor, K., et al. (2005) Type I receptor tyrosine kinases are associated with hormone escape in prostate cancer. J Pathol, Vol. 205, pp.522-529. 
Barton BE, Karras JG, Murphy TF, et al. (2004) Signal transducer and activator of transcription 3 (STAT3) activation in prostate cancer: direct STAT3 inhibition induces apoptosis in prostate cancer lines. Mol Cancer Ther 3: 11 - 20

Bleeker, F.E., Felicioni, L., Buttitta, F., et al. (2008) AKT1(E17K) in human solid tumours. Oncogene 2008.

Boormans JL, Korsten H, Ziel-van der Made AC, et al. (2010) E17K substitution in AKT1 in prostate cancer. BrJ Cancer, Vol. 102, pp.1491-1494.

Bruey, J.M., Paul, C., Fromentin, A., et al. (2000) Differential regulation of HSP27 oligomerization in tumor cells grown in vitro and in vivo. Oncogene, Vol. 19, pp. 4855-4863.

Bubendorf, L., Sauter, G., Moch, H., et al. (1996) Prognostic significance of Bcl-2 in clinically localized prostate cancer. Am J Pathol, Vol.148, pp.1557-1565.

Castilla, C., Congregado, B., Chinchón, D., et al. (2006) Bcl-xL is overexpressed in hormone-resistant prostate cancer and promotes survival of LNCaP cells via interaction with proapoptotic Bak. Endocrinology, Vol.147, pp.4960-7.

Chen, Y., Sawyers, C.L., Sche,r H.I. (2008) Targeting the androgen receptor pathway in prostate cancer. Curr Opin Pharmacol, Vol. 8, pp. 440-448.

Chen, C.D., Sawyers, C.L.(2002) NF-kappa B activates prostate-specific antigen expression and is upregulated in androgen-independent prostate cancer. Mol Cell Biol, Vol.22, pp. 2862-2870.

Chuan, Y.C., Pang, S.T., Cedazo-Minguez, A, et al. (2006) Androgen induction of prostate cancer cell invasion is mediated by ezrin. J Biol Chem, Vol.281, pp.29938-29948.

Concannon, C.G, Orrenius, S., Samali, A. (2000) Hsp27 inhibits cytochrome c-mediated caspase activation by sequestering both pro-caspase-3 and cytochrome c. Gene Expr, Vol. 9, pp.195-201.

Connolly JM, Rose DP. (1994) Regulation of DU145 human prostate cancer cell proliferation by insulin-like growth factors and its interaction with the epidermal growth factor autocrine loop. Prostate, Vol.24, pp.167-175.

Culig, Z., Hobisch, A., Cronauer, M.V. (1994) Androgen receptor activation in prostatic tumor cell lines by insulin-like growth factor-I, keratinocyte growth factor, and epidermal growth factor. Cancer Res, Vol. 54, pp. 5474-5478.

Curto, M., McClatchey, A.I. (2004) Ezrin...a metastatic detERMinant? Cancer Cell, Vol. 5, pp. 113-114.

Davies, M.A., Koul, D., Dhesi, H., et al. (1999) Regulation of Akt/PKB activity, cellular growth, and apoptosis in prostate carcinoma cells by MMAC/PTEN. Cancer Res, Vol.59, pp.2551-2556.

Dehm, S.M., Tindall, D.J.(2006) Molecular regulation of androgen action in prostate cancer. J Cell Biochem, Vol.99, pp.333-44.

Dehm, S.M., Schmidt, L.J., Heemers, H.V. (2008) Splicing of a novel androgen receptor exon generates a constitutively active androgen receptor that mediates prostate cancer therapy resistance. Cancer Res, Vol. 68, pp. 5469-5477.

DeMiguel, F., Lee, S.O., Lou, W., et al. (2002) Stat3 enhances the growth of LNCaP human prostate cancer cells in intact and castrated male nude mice. Prostate, Vol.52, pp.123-129. 
DeVere White, R.W., Vinall, R.L., Tepper, C.G., et al. (2009) MicroRNAs and their potential for translation in prostate cancer. Urol Oncol, Vol.27, pp.307-311.

Di Lorenzo, G., Tortora, G., D'Armiento, F.P. (2002) Expression of epidermal growth factor receptor correlates with disease relapse and progression to androgenindependence in human prostate cancer. Clin Cancer Res, Vol. 8, pp. 3438-3444.

Dorkin, T.J., Robinson, M.C., Marsh, C., et al. (1999) aFGF immunoreactivity in prostate cancer and its colocalization with bFGF and FGF8. Journal of Pathology, Vol.189, pp. 564-569.

Drachenberg, D.E., Elgamal, A.A., Rowbotham, R., et al. (1999) Circulating levels of interleukin-6 in patients with hormone refractory prostate cancer. Prostate, Vol.41, pp.127 - 133.

Edwards, J. (2010) Src kinase inhibitors: an emerging therapeutic treatment option for prostate cancer. Expert Opin Investig Drugs, Vol.19, pp.605-614.

Edwards, J., Traynor, P., Munro, A.., et al. (2006) The role of HER1-HER4 and EGFRvIII in hormone-refractory prostate cancer. Clin.Cancer Res, Vol.12, pp.123-130.

Edwards, J. and Bartlett, J.M.S. (2005) The androgen receptor and signal-transduction pathways in hormone-refractory prostate cancer. Part 2: Androgen-receptor cofactors and bypass pathways. BJU Int, Vol.95, pp.1327-1335.

Edwards, J., Krishna, N.S., Mukherjee, R., et al. (2004) The role of c-Jun and c-Fos expression in androgen-independent prostate cancer. J Pathol, Vol.204, pp.153 - 158.

Edwards, J., Krishna, N.S., Grigor, K.M., et al. (2003) Androgen receptor gene amplification and protein expression in hormone refractory prostate cancer. Br.J Cancer, Vol.89, pp.552-556.

Feilotter, H.E., Nagai, M.A., Boag, A.H., et al. (1998) Analysis of PTEN and the 10q23 region in primary prostate carcinomas. Oncogene, Vol. 16, pp.1743-1748.

Fenci, I., Woenckhaus, J. (2002) The tumour suppressor PTEN and the cell cycle inhibitor p27(KIP1) in prostate carcinoma and prostatic intraepithelial neoplasia (PIN) - An immunohistochemical study. British Journal of Cancer, Vol. 86, pp.S79-S80.

Fizazi, K., Yang, J., Peleg, S. et al. (2003) Prostate cancer cells-osteoblast interaction shifts expression of growth/survival-related genes in prostate cancer and reduces expression of osteoprotegerin in osteoblasts. Clin.Cancer Res, Vol. 9, pp.2587-2597.

Franco, O.E., Onishi, T., Yamakawa, K., et al. (2003) Mitogen-activated protein kinase pathway is involved in androgen-independent PSA gene expression in LNCaP cells. Prostate, Vol.56, pp.319 - 325.

Gao, S., Lee, P., Wang, et al. (2005) The Androgen Receptor Directly Targets the Cellular Fas/FasL-Associated Death Domain Protein-Like Inhibitory Protein Gene to Promote the Androgen-Independent Growth of Prostate Cancer Cells. Mol Endocrinol, 19, pp.1792-1802.

Garrido, C., Schmitt, E., Cande, C., et al. (2003) HSP27 and HSP70: potentially oncogenic apoptosis inhibitors. Cell Cycle, Vol.2, pp.579-584.

Gennigens, C., Menetrier-Caux, C., Droz, J.P. (2006) Insulin-Like Growth Factor (IGF) family and prostate cancer. Crit Rev Oncol Hematol, Vol.58, pp.124-145.

Gibbons, N.B., Watson, R.W., Coffey, R.N., et al. (2000) Heat-shock proteins inhibit induction of prostate cancer cell apoptosis.Prostate, Vol.45, pp.58-65. 
Gioeli, D., Mandell, J.W., Petroni, G.R., et al. (1999) Activation of mitogen-activated protein kinase associated with prostate cancer progression. Cancer Res, Vol.59, pp. 279 - 284.

Giri, D. \& Ittmann, M. (2001) Interleukin-8 is a paracrine inducer of fibroblast growth factor 2, a stromal and epithelial growth factor in benign prostatic hyperplasia. Am J Pathol, Vol.159, pp. 139-147.

Gowardhan, B., Douglas, D.A.,Mathers, M.E., et al. Evaluation of the fibroblast growth factor system as a potential target for therapy in human prostate cancer. Br J Cancer 2005;92:320-327.

Grasso, A.W., Wen, D., Miller, C.M., et al. (1997) ErbB kinases and NDF signaling in human prostate cancer cells. Oncogene, Vol.15, pp.2705-2716.

Gray, I.C., Stewart, L.M., Phillips, et al. (1998) Mutation and expression analysis of the putative prostate tumoursuppressor gene PTEN. Br J Cancer, Vol.78, pp.300.

Guo, Z., Dai, B., Jiang, T., et al. (2006) Regulation of androgen receptor activity by tyrosine phosphorylation. Cancer Cell, Vol.10, pp.309-319.

Guo, Z., Yang, X., Sun, F. (2009)A novel androgen receptor splice variant is up-regulated during prostate cancer progression and promotes androgen depletion-resistant growth. Cancer Res, Vol. 69, pp. 2305-13.

Han, G., Buchanan, G., Ittmann, M. (2005) Mutation of the androgen receptor causes oncogenic transformation of the prostate. Proc Natl Acad Sci U S A, Vol. 25, pp. 1151-6.

Heer, R., Douglas, D., Mathers, M.E., et al. (2004) Fibroblast growth factor 17 is overexpressed in human prostate cancer. J Pathol, Vol.204, pp.578-586.

Hitosugi, T., Sasaki, K., Sato, M., et al. (2007) Epidermal growth factor directs sex-specific steroid signaling through Src activation. J Biol Chem, Vol.282, pp.10697-10706.

Hernes, E., Fosså, S.D., Berner, A. (2004) Expression of the epidermal growth factor receptor family in prostate carcinoma before and during androgen-independence. Br J Cancer, Vol. 90, pp. 449-454.

Hobisch A, Eder IE, Putz T, et al. (1998) Interleukin-6 regulates prostate-specific protein expression in prostate carcinoma cells by activation of the androgen receptor. Cancer Res, Vol.58, pp.4640- 4645.

Hu, R., Dunn, T.A., Wei, S. (2009) Ligand-independent androgen receptor variants derived from splicing of cryptic exons signify hormone-refractory prostate cancer. Cancer Res, Vol. 69, pp.16-22.

Huang, S.Y., Pettaway, C.A., Uehara, H., et al. (2001) Blockade of NFkappa B activity in human prostate cancer cells is associated with suppression of angiogenesis, invasion, and metastasis. Oncogene, Vol.20, pp.4188-4197.

Huggins, C. \& Hodges, C.V. (1971) Studies on prostatic cancer: I. The effect of castration, of estrogen and of androgen injection on serum phosphatases in metastatic carcinoma of the prostate. Cancer Research, Vol.1, pp.293-297.

Jagla, M., Fève, M., Kessler, P. (2007) A splicing variant of the androgen receptor detected in a metastatic prostate cancer exhibits exclusively cytoplasmic actions.Endocrinology, Vol. 148, pp. 4334-4343.

Jasavala, R., Martinez, H., Thumar, J., et al. (2007) Identification of putative androgen receptor interaction protein modules: cytoskeleton and endosomes modulate 
androgen receptor signaling in prostate cancer cells. Mol Cell Proteomics. Vol.6, pp.252-271.

Kim, H.G., Kassis, J., Souto, J.C. (1999) EGF receptor signaling in prostate morphogenesis and tumorigenesis. Histol Histopathol, Vol. 14, pp. 1175-82.

Koumakpayi, I.H., Diallo, J.S., Le Page, C. (2006)Expression and nuclear localization of ErbB3 in prostate cancer. Clin Cancer Res, Vol. 12, pp.2730-2737.

Kirkegaard, T., Witton, C.J., Edwards, J., et al. (2010) Molecular alterations in AKT1, AKT2 and AKT3 detected in breast and prostate cancer by FISH. Histopathology, Vol., pp.

Krajewska, M., Krajewski, S., Epstein, J.I., et al. (1996) Immunohistochemical analysis of bcl-2, bax, bcl-X, and mcl-1 expression in prostate cancers. Am J Pathol, Vol.148, pp.1567-1576.

Kumar, A., Goel, A.S., Hill, T.M. (1996) Expression of human glandular kallikrein, hK2, in mammalian cells. Cancer Res, Vol. 56, pp. 5397-5402.

Kurahashi, T., Miyake, H., Hara, I., et al. (2001) Expression of major heat shock proteins in prostate cancer: correlation with clinicopathological outcomes in patients undergoing radical prostatectomy. J Urol, Vol. 177, pp.757-761.

Kwabi-Addo, B., Ropiquet, F., Giri, D., et al. (2001) Alternative splicing of fibroblast growth factor receptors in human prostate cancer. Prostate, Vol.46, pp.163-172.

Kwabi-Addo, B., Ozen, M., Ittmann, M. (2004) The role of fibroblast growth factors and their receptors in prostate cancer. Endocr Relat Cancer, Vol.11, pp.709-24.

Lammont, K.R., Tindall, D.J. (2010) Androgen regulation of gene expression Adv Cancer Res, Vol. 107, pp.137-162.

Lee, L.F., Guan, J., Qiu, Y., et al. (2001) Neuropeptide-induced androgen independence in prostate cancer cells: roles of nonreceptor tyrosine kinases Etk/Bmx, Src, and focal adhesion kinase. Mol Cell Biol, Vol.21, pp.8385-8397.

Lee, L.F., Louie, M.C., Desai, S.J., et al. (2004) Interleukin-8 confers androgen-independent growth and migration of LNCaP: differential effects of tyrosine kinases Src and FAK. Oncogene, Vol.23, pp.2197-2205.

Lee, S.O., Lou, W., Johnson, C.S., et al. (2004) Interleukin-6 protects LNCaP cells from apoptosis induced by androgen deprivation through the Stat 3 pathway. Prostate, Vol.60, pp.178 - 186.

Le Page, C., Koumakpayi, I.H., Alam-Fahmy, M., et al. (2006) Expression and localisation of Akt-1, Akt-2 and Akt-3 correlate with clinical outcome of prostate cancer patients. Br J Cancer, Vol.94, pp. 1906-1912.

Leon, C.G., Locke, J.A., Adomat, H.H., et al. (2010) Alterations in cholesterol regulation contribute to the production of intratumoral androgens during progression to castration-resistant prostate cancer in a mouse xenograft model. Prostate, Vol.70, pp.390-400.

Li, X., Marani, M., Mannucci, R., et al. (2001) Overexpression of BCL-XL underlies the molecular basis for resistance to staurosporine-induced apoptosis in PC-3 cells. Cancer Res, Vol.61, pp.1699-1706.

Liao, Y., Grobholz, R., Abel, U., et al. (2003) Increase of AKT/PKB expression correlates with gleason pattern in human prostate cancer. Int J Cancer, Vol.107, pp.676-680. 
Lin, B., Wang, J., Hong, X., et al. (2009) Integrated expression profiling and ChIP-seq analyses of the growth inhibition response program of the androgen receptor. PLoS One, Vol.4, pp.e6589.

Locke, J.A., Wasan, K.M., Nelson, C.C., et al. (2008) Androgenmediated cholesterol metabolismin LNCaPand PC-3 cell lines is regulated through two different isoforms of acyl-coenzyme A:cholesterol acyltransferase (ACAT). Prostate, Vol.68, pp.20-33.

Malik, S.N., Brattain, M., Ghosh, P.M., et al. (2002) Immunohistochemical demonstration of phospho-Akt in high Gleason grade prostate cancer. Clin Cancer Res, Vol.8, pp. 1168-1171.

Marcelli, M., Marani, M., Li, X., et al. (2000) Heterogeneous apoptotic responses of prostate cancer cell lines identify an association between sensitivity to staurosporine-induced apoptosis, expression of Bcl-2 family members, and caspase activation. Prostate, Vol.42, pp.260-273.

McCall, P., Gemmell, L.K., Mukherjee, R., et al. (2008) Phosphorylation of the Androgen Receptor is associated with reduced survival in hormone refractory prostate cancer patients. Br J Cancer, Vol.98, pp.1094-1101.

McCall, P., Witton, C.J., Nielsen, K.V., et al. (2008). Is PTEN loss associated with clinical outcome measures in human prostate cancer? Br J Cancer, Vol.99, pp.1296-1301.

McDonnell, T.J., Troncoso, P., Brisbay, S.M., et al. (1992) Expression of the protooncogene bcl-2 in the prostate and its association with emergence of androgen-independent prostate cancer. Cancer Res, Vol.52, pp.6940-6944.

McMenamin, M.E., Soung, P., Perera, S., et al. (1999) Loss of PTEN expression in paraffinembedded primary prostate cancer correlates with high Gleason score and advanced stage. Cancer Res, Vol.59, pp. 4291- 4296.

Mellinghoff, I,K,, Vivanco, I,, Kwon, A. (2004) HER2/neu kinase-dependent modulation of androgen receptor function through effects on DNA binding and stability. Cancer Cell, Vol. 6, pp.517-527.

Mimeault, M., Pommery, N., Hénichart, J.P. (2003) New advances on prostate carcinogenesis and therapies: involvement of EGF-EGFR transduction system. Growth Factors, Vol. 21, pp. 1-14.

Montgomery, J.S., Price, D.K., Figg, W.D. (2001) The androgen receptor gene and its influence on the development and progression of prostate cancer. J Pathol, Vol.195, pp.138-46.

Memarzadeh, S., Xin, L., Mulholland, D.J., et al. (2007) Enhanced paracrine FGF10 expression promotes formation of multifocal prostate adenocarcinoma and an increase in epithelial androgen receptor. Cancer Cell, Vol.12, pp.572-85.

Migliaccio, A., Castoria, G., Di Domenico, M., et al. (2000) Steroid-induced androgen receptor-oestradiol receptor beta-Src complex triggers prostate cancer cell proliferation. EMBO J, Vol.19, pp.5406-5417.

Migliaccio, A., Di Domenico, M., Castoria, G., et al. (2005) Steroid receptor regulation of epidermal growth factor signaling through $\mathrm{Src}$ in breast and prostate cancer cells: steroid antagonist action. Cancer Res, Vol.65, pp.10585-10593. 
Mukherjee, R., McGuinness, D.H., McCall, P. (2011) Upregulation of MAPK pathway is associated with survival in castrate-resistant prostate cancer. Br J Cancer, Vol.104, pp.1920 - 1928.

Murillo, H., Huang, H., Schmidt, L.J., et al. (2001) Role of PI3K Signaling in Survival and Progression of LNCaP Prostate Cancer Cells to the Androgen Refractory State. Endocrinology, Vol.142, pp.4795-4805.

Nakae, J., Kido, Y., Accili, D. (2001). Distinct and overlapping functions of insulin and IGF-I receptors. Endocrine Rev, Vol.22, pp.818-835.

Nam, S., Kim, D., Cheng, J.Q. (2005) Action of the Src family kinase inhibitor, dasatinib (BMS-354825), on human prostate cancer cells. Cancer Res, Vol. 65, pp. 9185-9189.

Ngan, S., Stronach, E.A., Photiou, A., et al. (2009) Microarray coupled to quantitative RTPCR analysis of androgen-regulated genes in human LNCaP prostate cancer cells. Oncogene, Vol.28, pp.2051-2063.

Ngo, T.H., Barnard, R.J., Leung, P.S. et al. (2003) Insulin-like growth factor I (IGF-I) and IGF binding protein-1 modulate prostate cancer cell growth and apoptosis: possible mediators for the effects of diet and exercise on cancer cell survival. Endocrinology, Vol.144, pp.2319-2324.

Nylandsted, J., Brand, K., Jäättelä, M. (2000) Heat shock protein 70 is required for the survival of cancer cells. Ann N Y Acad Sci, Vol.926, pp.122-125.

Okegawa, T., Kinjo, M., Nutahara, K. (2006) Pretreatment serum level of HER2/nue as a prognostic factor in metastatic prostate cancer patients about to undergo endocrine therapy. Int J Urol, Vol. 13, pp. 1197-1201.

Pandini, G., Mineo, R., Frasca, F., et al. (2005) Androgens up-regulate the insulin-like growth factor-I receptor in prostate cancer cells. Cancer Res, Vol. 65, pp.1849-1857.

Pandini, G., Genua, M., Frasca, F., et al. (2007) 17beta-estradiol up-regulates the insulinlike growth factor receptor through a nongenotropic pathway in prostate cancer cells. Cancer Res, Vol.67, pp.8932-8941.

Paul, C., Manero, F., Gonin, S., et al. (2000) Hsp27 as a negative regulator of cytochrome C release. Mol Cell Biol, Vol.22, pp. 816-34.

Pienta, K.J., Bradley, D. (2006) Mechanisms underlying the development of androgenindependent prostate cancer. Clin Cancer Res, Vol. 15, pp. 1665-71.

Raclaw, K.A., Heemers, H.V., Kidd, E.M., et al. (2008) Induction of FLIP expression by androgens protects prostate cancer cells from TRAIL-mediated apoptosis. Prostate, Vol.68, pp.1696-706.

Recchia, I., Rucci, N., Festuccia, C. (2003) Pyrrolopyrimidine c-Src inhibitors reduce growth, adhesion, motility and invasion of prostate cancer cells in vitro. Eur J Cancer, Vol. 39, pp. 1927-1935.

Rocchi, P., So, A., Kojima, S., et al. (2004) Heat shock protein 27 increases after androgen ablation and plays a cytoprotective role in hormone-refractory prostate cancer. Cancer Res, Vol.64, pp.6595-602.

Rocchi, P., Beraldi, E., Ettinger, S., et al. (2005) Increased Hsp27 after androgen ablation facilitates androgen-independent progression in prostate cancer via signal transducers and activators of transcription 3-mediated suppression of apoptosis. Cancer Res, Vol.65, pp.11083-93. 
Rochette-Egly, C. (2003) Nuclear receptors: integration of multiple signalling pathways through phosphorylation. Cell Signal, Vol.15, pp.355-366.

Romashkova, J.A., Makarov, S.S. (1999) NF-kappaB is a target of AKT in antiapoptotic PDGF signalling. Nature, Vol.401, pp.86-90.

Ropiquet, F., Giri, D., Kwabi-Addo, B., et al. (2000) Increased expression of fibroblast growth factor 6 in human prostatic intraepithelial neoplasia and prostate cancer. Cancer Research, Vol.60, pp.4245-4250.

Sahadevan, K., Darby, S., Leung, H.Y. (2007) Selective over-expression of fibroblast growth factor receptors 1 and 4 in clinical prostate cancer. J Pathol, Vol. 213, pp. 82-90.

Sarker, D., Reid, A.H.M., Yap, T.A., et al. (2009) Targeting the PI3K/AKT Pathway for the Treatment of Prostate Cancer. Clin Cancer Res, Vol.15, pp.4799-4805.

Samuels, Y., Wang, Z., Bardelli, A., et al. (2004) High frequency of mutations of the PIK3CA gene in human cancers. Science Vol.304, pp.554.

Schayek, H., Seti, H., Greenberg, N.M., et al. (2010) Differential regulation of insulin-like growth factor-I receptor gene expression by wild type and mutant androgen receptor in prostate cancer cells. Mol Cell Endocrinol, Vol.323, pp.239-45.

Shiota, M., Yokomizo, A., Naito, S. (2011) J Increased androgen receptor transcription: a cause of castration-resistant prostate cancer and a possible therapeutic target. $\mathrm{Mol}$ Endocrinol, Apr 19.

Shukla, S., MacLennan, G.T., Hartman, D.J., et al. (2007) Activation of PI3K-Akt signaling pathway promotes prostate cancer cell invasion. Int J Cancer, Vol.121, pp.14241432.

Sidenius, N. \& Blasi, F. (2003) The urokinase plasminogen activator system in cancer: recent advances and implication for prognosis and therapy. Cancer Metastasis Reviews, Vol.22, pp.205-222.

Slack, J.K., Adams, R.B., Rovin, J.D, et al. (2001) Alterations in the focal adhesion kinase/Src signal transduction pathway correlate with increased migratory capacity of prostate carcinoma cells. Oncogene, Vol.20, pp.1152-63.

Suh, J., Payvandi, F., Edelstein, L.C., et al. (2002) Mechanisms of constitutive NF-kappaB activation in human prostate cancer cells. Prostate, Vol.52, pp.183-200.

Sumitomo, M., Shen, R., Walburg, M., et al. (2000) Neutral endopeptidase inhibits prostate cancer cell migration by blocking focal adhesion kinase signaling. J Clin Invest, Vol.106, pp.1399-1407.

Sun, X., Huang, J., Homma, T., et al. (2009) Genetic alterations in the PI3K pathway in prostate cancer. Anticancer Res, Vol.29, pp.1739-1743.

Suzuki, H., Freije, D., Nusskern, D.R., et al. (1998) Interfocal heterogeneity of PTEN/MMAC1 gene alterations in multiple metastatic prostate cancer tissues. Cancer Res, Vol.58, pp.204-209.

Tam, L., McGlynn, L.M., Traynor, P., et al. (2007) The Role of IL-6R/JAK/STAT3 Pathway in Hormone Refractory Prostate Cancer. Br J Cancer, Vol.97, pp.378-383.

Takayama, K., Horie-Inoue, K., Ikeda, K., et al. (2008) FOXP1 is an androgen-responsive transcription factor that negatively regulates androgen receptor signaling in prostate cancer cells. Chem Biophys Res Commun, Vol.374, pp.388-93.

Tatarov, O., Mitchell, T.J., Seywright, M. (2009) SRC family kinase activity is up-regulated in hormone-refractory prostate cancer. Clin Cancer Res, Vol. 15, pp. 3540-3549. 
Tepper, C.G., Boucher, D.L., Ryan, P.E. (2002) Characterization of a novel androgen receptor mutation in a relapsed CWR22 prostate cancer xenograft and cell line. Cancer Res, Vol. 62, pp. 6606-6614.

Teo, K., Gemmell, L., Mukherjee, R. (2007) Bad expression influences time to androgen escape in prostate cancer. BJU Int, Vol.100, pp.691-696.

Udayakumar, T.S., Nagle, R.B., Bowden, G.T. (2004) Fibroblast growth factor-1 transcriptionally induces membrane type-1 matrix metalloproteinase expression in prostate carcinoma cell line. Prostate, Vol.58, pp.66-75.

Ueda, T., Bruchovsky, N., Sadar, M.D. (2002) Activation of the androgen receptor Nterminal domain by interleukin-6 via MAPK and STAT3 signal transduction pathways. J Biol Chem, Vol.277, pp.7076- 7085.

Valta, M.P., Hentunen, T., Qu, Q., et al. (2006) Regulation of osteoblast differentiation: a novel function for fibroblast growth factor 8. Endocrinology, Vol. 147, pp. 21712182.

Valta, M. P., Tuomela, J., Bjartell, A., et al. (2008) FGF-8 is involved in bone metastasis for prostate cancer. Int J Cancer, Vol. 123, pp.22-31.

Veldscholte, J., Berrevoets, C.A., Brinkmann, A.O., et al. (1992) Anti-androgens and the mutated androgen receptor of $\mathrm{LNCaP}$ cells: differential effects on binding affinity, heat-shock protein interaction, and transcription activation. Biochemistry, Vol.31, pp.2393-2399.

Verhagen, P.C., van Duijn, P.W., Hermans, K.G., et al. (2006) The PTEN gene in locally progressive prostate cancer is preferentially inactivated by bi-allelic gene deletion. J Pathol, Vol. 208, pp.699-707.

Wang, J., Stockton, D.W., Ittmann, M. (2004) The fibroblast growth factor receptor-4 Arg388 allele is associated with prostate cancerinitiation and progression. Clin Cancer Res, Vol.10, pp.6169-6178.

Wen, Y., Hu, M.C., Makino, K. (2000) HER-2/neu promotes androgen-independent survival and growth of prostate cancer cells through the Akt pathway. Cancer Res, Vol. 60, pp. 6841-6845.

Weinstein-Oppenheimer, C.R., Blalock, W.L., Steelman, L.S., et al. (2000) The Raf signal transduction cascade as a target for chemotherapeutic intervention in growth factor-responsive tumors. Pharmacol Ther, Vol. 88, pp.229 - 279.

Wu, J.D., Haugk, K., Woodke, L. et al. (2006) Interaction of IGF signaling and the androgen receptor in prostate cancer progression. J. Cell Biochem, Vol.99, pp. 392401.

Yeh, S., Lin, H.K., Kang, H.Y. (1999) From HER2/Neu signal cascade to androgen receptor and its coactivators: a novel pathway by induction of androgen target genes through MAP kinase in prostate cancer cells. Proc Natl Acad Sci U S A, Vol. 96, pp. 5458-5463.

Yeh, S., Lin, H.K., Kang HY, et al. (1999) From HER2/Neu signal cascade to androgen receptor and its coactivators: a novel pathway by induction of androgen target genes through MAP kinase in prostate cancer cells. Proc Natl Acad Sci U S A, Vol.96, pp.5458-5463. 
Yoshimoto, M., Cunha, I.W., Coudry, R.A., et al. (2007) FISH analysis of 107 prostate cancers shows that PTEN genomic deletion is associated with poor clinical outcome. Br J Cancer, Vol.97, pp.678-685.

Yoshino, T., Shiina, H., Urakami, S., et al. (2006) Bcl-2 expression as a predictive marker of hormone-refractory prostate cancer treated with taxane-based chemotherapy. Clin Cancer Res, Vol.12, pp.6116-6124. 


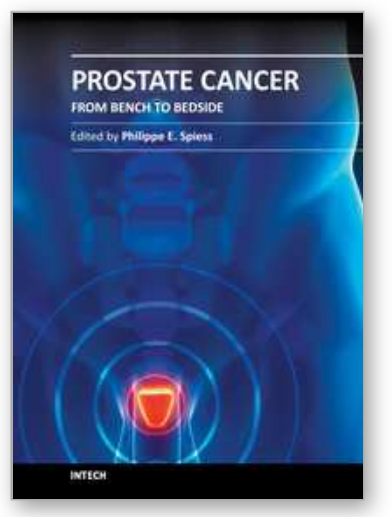

\section{Prostate Cancer - From Bench to Bedside}

Edited by Dr. Philippe E. Spiess

ISBN 978-953-307-331-6

Hard cover, 528 pages

Publisher InTech

Published online 25, November, 2011

Published in print edition November, 2011

The present textbook highlights many of the exciting discoveries made in the diagnosis and treatment of prostate cancer over the past decade. International thought leaders have contributed to this effort providing a comprehensive and state-of-the art review of the signaling pathways and genetic alterations essential in prostate cancer. This work provides an essential resource for healthcare professionals and scientists dedicated to this field. This textbook is dedicated to the efforts and advances made by our scientific community, realizing we have much to learn in striving to some day in the not too distant future cure this disease particularly among those with an aggressive tumor biology.

\section{How to reference}

In order to correctly reference this scholarly work, feel free to copy and paste the following:

Sophia Marsella-Hatziieremia, Pamela McCall and Joanne Edwards (2011). Signalling Pathways and Gene Expression Profiles in Prostate Cancer, Prostate Cancer - From Bench to Bedside, Dr. Philippe E. Spiess (Ed.), ISBN: 978-953-307-331-6, InTech, Available from: http://www.intechopen.com/books/prostate-cancer-frombench-to-bedside/signalling-pathways-and-gene-expression-profiles-in-prostate-cancer

\section{INTECH}

open science | open minds

\section{InTech Europe}

University Campus STeP Ri

Slavka Krautzeka 83/A

51000 Rijeka, Croatia

Phone: +385 (51) 770447

Fax: +385 (51) 686166

www.intechopen.com

\section{InTech China}

Unit 405, Office Block, Hotel Equatorial Shanghai

No.65, Yan An Road (West), Shanghai, 200040, China

中国上海市延安西路65号上海国际贵都大饭店办公楼405单元

Phone: +86-21-62489820

Fax: +86-21-62489821 
(C) 2011 The Author(s). Licensee IntechOpen. This is an open access article distributed under the terms of the Creative Commons Attribution 3.0 License, which permits unrestricted use, distribution, and reproduction in any medium, provided the original work is properly cited. 